\title{
CONTEXTOS TEMPORAIS EM SÍTIOS DE PINTURAS RUPESTRES, EM MORRO DO CHAPÉU, BAHIA
}

\section{TEMPORAL CONTEXTS IN ROCK PAINTINGS SITES IN MORRO DO CHAPEU, BAHIA}

\author{
Carlos Etchevarne ${ }^{1}$ \\ etchevarnebahia@gmail.com \\ Maria Conceição Soares Meneses Lage ${ }^{2}$ \\ meneses.lage@gmail.com \\ Benedito Batista Farias Filho ${ }^{3}$ \\ beneditofarias@ufpi.edu.br \\ Francisco Eroni Paz dos Santos ${ }^{4}$ \\ franciscoeroni@gmail.com
}

\section{RESUMO}

A determinação de demarcadores cronológicos em sítios de pinturas rupestres tem sido um dos objetivos fundamentais dos arqueólogos que trabalham nesse campo da Arqueologia. Em Morro do Chapéu, Bahia, às características limitantes dos vestígios, impedindo a aplicação de métodos tradicionais de datação, soma-se, a escassa acumulação de solos, que resultam em pouca profundidade e parcos artefatos acumulados. $\mathrm{O}$ achado de blocos de pigmentos dentro de fogueiras datadas, no Sítio Toca da Figura, proporciona condições impares para proporcionar um ponto temporal, tanto procurado. O uso de métodos analíticos da área Arqueometria tornou possível um quadro de vinculações entre as figuras representadas no painel do abrigo e os blocos de pigmentos das fogueiras.

Palavras-chave: Pintura rupestre; Chapada Diamantina/ BA; Arqueometria.

\footnotetext{
${ }^{1}$ Universidade Federal da Bahia.

${ }^{2}$ Universidade Federal do Piauí-Curso de Arqueologia.

${ }^{3}$ Universidade Federal do Piauí-Departamento de Química.

${ }^{4}$ Universidade Federal do Piauí-Departamento de Física.
} 


\begin{abstract}
The definitions of chronological markers of painting on rock art in Archeological sites, has been one of fundamental aiming for all searchers that work in Archeology. In Morro do Chapéu-Ba, limited features of traces are the main reason that make difficult to use traditional methods. In addition, it worst with shallow depth soil, resulting scarce and poor artefacts. However, the finding of pigment blocks inside of campfire in the Toca da Figura, provides exceptional opportunity to determine when it was done. The use of analytical methods from Archeometry became possible to build a frame of links between pictures painted on the panel and the pigment blocks of campfire.
\end{abstract}

Keywords: Rock painting; Chapada Diamantina / BA; Archeometry.

\title{
O TERRITÓRIO DE MORRO DO CHAPÉU, AMBIENTE NATURAL E INCIDÊNCIA DE SÍTIOS DE ARTE RUPESTRE
}

Morro do Chapéu está localizado no extremo noroeste NO da Chapada Diamantina.

O extenso território municipal oferece paisagens variadas, que dependem, fundamentalmente, do tipo de substrato rochoso, que, enquanto emergente, foi modelado pela geodinâmica regional.

De fato, existem diferenças acentuadas em termos de relevo, nas áreas onde predominam os afloramentos de arenitos, daquelas onde se encontram os relevos calcários, que, geologicamente, formam parte da bacia de Irecê. Compreender a distinção entre os diferentes domínios estruturais geológicos, seus modelamentos e formas atuais, é fundamental para identificar as opções entre os tipos de espaços passíveis de serem ocupados por grupos de caçadores coletores ou de horticultores, em tempos anteriores à colonização portuguesa. 
Os arenitos, especialmente os que passaram pelo processo de silicificação, formam grandes conjuntos litológicos de acamamentos sobrepostos, com divisões horizontais visíveis a olho nu, produtos que são dos diferentes momentos geológicos de acumulação de sedimentos areníticos marinhos. As camadas ou estratos dão um caráter particular aos conjuntos parecendo imensas construções de blocos montados.

Após a elevação por movimentação tectônica da grande massa da atual Chapada Diamantina, os processos erosivos eólicos e pluviais, além dos movimentos de dilatação e contração pelo efeito da insolação, atuantes durante milhões de anos provocando desgastes e consequentes retrações das paredes dos acamamentos, especialmente na base deles.

Alguns exemplos podem ser oferecidos imediatamente, para ilustrar o que acaba de ser exposto. Os afloramentos de Igrejinha, que são avistadas de múito longe, emergem na beira do vale profundo do Rio Ventura, assemelhando-se a torres sineiras de templos católicos, motivo pelo qual a localidade é denominada de Igrejinha, desde o tempo da mineração do diamante.

Outro exemplo claro desta configuração o oferece o Complexo Arqueológico Lagoa da Velha. Corresponde a um conjunto de afloramentos dispostos aproximadamente em forma semicircular, com uma depressão no meio, que atualmente só enche de 
água no período de chuvas. Nesse complexo tem vários abrigos e paredões com muitos painéis com figuras, que remetem a estilos pictóricos conhecidos.

Assim, foram se configurando os relevos atuais emergentes, que proporcionam, em muitos setores, reentrâncias acentuadas, por níveis horizontais, bem definidos pela dureza dos blocos acamados e pela reação deles à força dos intemperismos. De fato, cada camada respondeu de forma diferente e por isso reentrou também em profundidade diferente à de outros blocos. O resultado visível em perfil são as formas de marquises, tocas ou lapas, a depender de quanto se aprofundam para o interior do afloramento, sendo algumas delas ideais para a proteção de grupos humanos pouco numerosos, em períodos de curta e média permanência. Na parte interna de certos abrigos e nos paredões anexos a eles, essas populações encontraram os suportes ideais para executar painéis com grafismos pintados. $\mathrm{O}$ município tem numerosos locais desse tipo, o que demonstra a preferência por esses espaços e a intensa ocupação dos mesmos, em tempos pré-coloniais.

É importante de ser lembrado que a superfície dos blocos que fica exposta de forma vertical apresenta, em muitos casos, um nível de alisamento que é ideal para a execução de pinturas que exigem um grau de aprimoramento no traço, como por exemplo, as miniaturas. A homogeneidade da fina granulométrica, típica dos arenitos silicificados, o desprendimento natural da rocha em forma conchoidal, e os efeitos do desgaste de ventos e chuvas, formaram superfícies alisadas que devem ter chamado a atenção dos grupos pintores de pequenas figuras, ainda que, 
certamente, não deveria ser o único elemento que considerariam para definir a escolha de certos abrigos.

Em resumo, pode-se dizer que com relação aos demais municípios baianos, o território de Morro do Chapéu conta com a maior quantidade de sítios de arte rupestre já registrados na Bahia, a maioria deles em locais abrigados situados nos domínios dos arenitos, prevalecendo estilos naturalísticos de grande expressão realística, de pequenas dimensões e com policromia. Desta forma, fica evidente o fato que as condições de habitabilidade nesses abrigos eram bastante propícias, para curtas e medianas permanências.

\section{A TEMPORALIDADE DA OCUPAÇÃO DOS ABRIGOS PINTADOS EM MORRO DO CHAPÉU: UMA QUESTÃO IMPERATIVA.}

As pinturas rupestres constituem um tipo de vestígios arqueológicos que comportam algumas dificuldades de interpretação, entre outras, o estabelecimento de algum marco cronológico, com datações absolutas, das pinturas. Em que pese se tratar de locais de manifesta interação social, tendo em vista a densidade e sobreposições de figuras, os locais com pinturas e os próprios grafismos pintados são de difícil atribuição temporal. Isso se deve em parte à própria natureza dos pigmentos, que são na sua maioria de origem mineral, não havendo até o presente, métodos físico químicos que permitam datá-los ${ }^{5}$.

\footnotetext{
${ }^{5}$ Uma tentativa de datação, em Toca da Figura, foi realizada em 2011, quando foi convocado o físico Gelvam Hassertmann, do Instituto de Geofísica da USP, para aplicar o método por paleomagnetismo
} 
Mas, existe outro aspecto impeditivo de ordem topográfica e pedológica. Nem todos os sítios com pinturas podem ser escavados. Boa parte deles está coberta com blocos e detritos desprendidos das paredes rochosas, de forma que não há condições de alcançar o solo sedimentar, se por acaso este existir, de forma direta. Efetivamente, a acumulação de material desprendido das paredes e tetos parece ser anterior às ocupações dos grupos pintores, levando em conta que nenhum bloco acumulado no solo apresenta traços de pintura.

Há que considerar, ainda, o fato de que, em alguns casos, como os de Toca da Figura, Toca da Onça, Toca do Pepino e os vários abrigos de Lagoa da Velha, os solos, compostos essencialmente de areias quartzíticas resultantes da desintegração das rochas, são rasos, alcançando, nos raros pontos mais profundos, o nível de 50 $\mathrm{cm}$. Na parte inferior, o estrangulamento erosivo dos afloramentos resulta, por um

, já usado com sucesso no material cerâmico colonial, coletado nas pesquisas da Praça da Sé de Salvador. Não obstantes os esforços realizados por Hassertmann, dificuldades na própria coleta de amostras em campo, impediram chegar a um resultado satisfatório.

Ainda no município de Morro do Chapéu, no complexo arqueológico Lagoa da Velha, no Afloramento/Abrigo 1, apesar de o solo alcançar uma profundidade de $40 \mathrm{~cm}$, restos de carvões de fogueira foram coletados e datados em 2.270_+30BP, mas não houve nenhum vestígio que permitisse associar a data com um tipo de representação gráfica presentes no sítio.

Ainda na Chapada Diamantina, no sítio Serra das Paridas, município de Lençóis, a equipe de pesquisa Bahia Arqueológica, realizou escavações em um abrigo arenítico, próximo aos painéis pintados. No sítio, foram encontradas duas fogueiras, com marcadas depressões no solo arenoso, dentro das quais havia algumas lascas, confeccionadas do mesmo arenito dos afloramentos. Não se encontraram pigmentos, mas a ocupação humana está confirmada pela datação dos carvões que proporcionou um marco cronológico de 8.390 +_ $30 \mathrm{BP}$. 
lado, na desintegração das rochas (por desaparecimento da matriz silicosa), e por outro, deixa acúmulos de areia de pouca espessura, que seria o piso de habitação. Imediatamente embaixo desse solo arenoso, reaparece o substrato arenítico consolidado e duro, indicando que se chega a um estrato estéril intransponível. Isto quer dizer que o que tiver que ser encontrado de vestígio sempre será a pouca profundidade.

Com o objetivo de proporcionar dados contextuais culturais e temporais às pinturas rupestres de Morro do Chapéu, desenvolveu-se, nos últimos anos, um programa de escavações nos abrigos, que permitiram a coleta de carvões de fogueiras de tamanhos diferentes, em que resultaram três datações por C14, duas em Toca da Figura e outra no Afloramento 1 de Lagoa da Velha ${ }^{6}$.

\section{Os trabalhos de campo em Toca da Figura}

Toca da Figura é um afloramento típico dos arenitos dessa região morrense, formado por um abrigo com ampla marquise, e com uma fenda transversal

\footnotetext{
${ }^{6}$ As escavações, assim como outras atividades de caráter social (principalmente educativas), foram realizadas no âmbito de um grande projeto denominado "Circuitos Arqueológicos de visitação da Chapada Diamantina". O projeto, sustentado por um convênio entre a Universidade Federal da Bahia e o governo do Estado da Bahia, através do Instituo de Patrimônio Artístico e Cultural (IPAC), entre 2012 e 2015, previa a confecção de roteiros culturais elaborados pelos próprios membros das comunidades em cujos territórios os sítios estão localizados. O projeto, já em processo de implementação, viu-se interrompido no momento da mudança de governo estadual, com diretrizes diferentes para políticas culturais.
} 
acentuada. $\mathrm{O}$ afloramento se continua sob a forma de um paredão pouco protegido. Esta morfologia descontínua configura âmbitos espaciais diferenciados, com respectivas potencialidades diversas de uso.

A parte coberta por uma grande marquise, denominada Abrigo I, apresenta superfícies de proteção e alturas irregulares, mas que, no todo, constitui um espaço adequado para a instalação de um grupo humano pouco numeroso. Existem, ainda, sobressaindo do chão dois blocos de arenito, que correspondem a desprendimentos do teto. O menor deles, por se encontrar no centro do abrigo, pode ter sido utilizado como equipamento de apoio à instalação humana. De fato, duas fogueiras, uma de cada extremo do bloco foram achadas o que poderia indicar que o bloco teria servido de apoio ou de assento. Durante o processo de escavação, conseguiu-se abundante quantidade de carvão nas duas concentrações de combustão, das quais foram coletadas amostras que serviram para datar por C14.

As pinturas rupestres espalham-se por toda a extensão do abrigo e do paredão contíguo. O seu caráter figurativo e presença de associações entre elas formando cenas permitiram a inserção de algumas delas na Tradição Nordeste, bem como outras menos elaboradas mas também figurativas na tradição Agreste, ainda que possam ser observados elementos geométricos, isolados e bem elaborados. Uma dessas composições geométricas encontra-se na parte alta da marquise, de modo a ser vista logo na entrada, chamando a atenção também por ser tri cromática (amarelo, branco e vermelho). 
As convencionais figuras de matriz gráfica naturalística, dita Tradição Nordeste, dominam os painéis, como acontece em quase todos os sítios de pintura do Município de Morro do Chapéu. Estendendo-se pela parede do abrigo e do paredão, as figuras formam concentrações cenográficas diferentes, podendo-se encontrar motivos de beligerância entre grupos humanos (com suas armas nas mãos), coleta de frutos de palmeira, enfileiramentos de figuras antropomorfas, assim como conjuntos de emas, orientadas para uma mesma direção, em pigmento branco. Há uma composição de pequenas dimensões, que merece a atenção. São figurinhas humanas que representam duas situações sociais bem opostas. Um grupo carrega grandes sacolas nas costas dirigindo-se para a esquerda. À direita, sobre o mesmo plano, encontra-se um assentamento composto por pequenos grupos de pessoas dentro de cabanas. A oposição entre um e outro grupo está bem marcada, os que vão com sacolas, em movimento, e os que ficam, dentro das palhoças, fixos.

Por sua vez, os grafismos de matriz estilística da Tradição Agreste estão representados, como é de se esperar, por figuras humanas, de tamanho maior que as anteriormente citadas, superando alguns os $50 \mathrm{~cm}$. São corpos humanos isolados e sem muita ou nenhuma expressão gestual. As figuras de animais também são hieráticas e de difícil identificação de espécies, podendo ser reconhecido apenas se são quadrúpedes ou bípedes. 
Já as figuras geométricas, alcançam o máximo da síntese e simplificação, ou seja, nada naturalístico é possível ser reconhecido, como por exemplo, composições de círculos concêntricos e traços radiais que os dividem, muito frequentes na Chapada Diamantina e em outras partes da Bahia. Um caso especial está constituído pelo motivo da entrada do abrigo, já citado, que corresponde a uma sucessão de semicírculos, retângulos divididos internamente por linhas longitudinais, com um complemento formado por uma linha transversal com bastonetes transversais, na cor branca.

Para compreender, do ponto de vista temporal, a presença de motivos no sítio Toca da Figura, devemos contextualizar brevemente com o que acontece em outros sítios já estudados. Os motivos realísticos, compondo cenas e com grande expressão gestual, aparecem ocupando a primeira posição no painel, ou seja, foram os que inauguraram a sucessão de pinturas. Depois lhe sucedem figuras antropomorfas e zoomorfas que vão perdendo a vivacidade e a natureza narrativa. São corpos humanos e de animais que se tornam rígidos, geometrizados e aumentados em volume. O corpo começa a ser utilizado para outro tipo de informação codificada, passando a ser um suporte de sinais gráficos com atributos significativos, dispostos organizadamente nos corpos que são desenhados retangulares.

A partir desse momento comprova-se uma complexidade in crescente dos corpos, a par que os conjuntos cênicos vão desaparecendo. Paralelamente há um outro caminho para a transformação dos grafismos realistas. Os corpos humanos e de animais se avolumam e em muitos casos ganham musculatura. Aparecem os pés e 
as mãos, antes pouco frequentes, e aumentam os olhos, em cabeças reduzidas de tamanho. Inequivocamente, uma intenção deliberada no aumento dos órgãos da visão que sugerem valorização em seus atributos funcionais.

Nos últimos momentos gráficos, identificados pelo fato de serem os que aparecem mais superficiais nos painéis, são irreconhecíveis suas morfologias em termos de representação realística. São figuras compostas por linhas retas, formando grades, pentes, traços paralelos, ou curvas com círculos concêntricos, principalmente, organizados em grupos ou isolados, em posição de muita visibilidade.

\section{As escavações em Toca da Figura e as fogueiras com restos de pigmentos}

As nove quadras escavadas, na parte central do abrigo, apresentaram situação estratigráfica parecida, em termos de sedimentação natural e na presença de material arqueológico. A camada mais superficial estava composta por solo solto, arenoso, de cor escura devido ao abundante conteúdo orgânico e lascas de material arenítico do próprio abrigo. A segunda camada está formada por solo também arenoso, porém mais claro e menos antropizado, com pouco material lascado. Na terceira camada misturam-se blocos de rocha, que formam o afloramento, com areias bege ligeiramente avermelhadas. Nesta camada não há material arqueológico.

De todas as quadras escavadas a que proporcionou dados inéditos foi a número 5 , onde foi encontrada a primeira fogueira, próximo ao bloco arenítico de rocha 
emergente no chão. O material combustível foi colocado dentro de uma depressão de uns $40 \mathrm{~cm}$, cavada propositalmente, para aumentar o poder calorífero da lenha. Nesta quadra os primeiros carvões aparecem a partir dos $15 \mathrm{~cm}$ da superfície, que aumentam em volume e dimensão à medida que se aprofunda. Aos $40 \mathrm{~cm}$, a densidade de carvão aumentou, calculando-se em $2 \mathrm{~kg}$ o peso total.

Dentro dessa fogueira foi coletado um fragmento de seixo de quartzo branco, em cujo córtex observa-se uma mancha de coloração avermelhada, provável marca de produção de pigmento. Ademais coletaram-se 3 blocos pequenos de hematita. $\mathrm{O}$ maior deles, de $10 \mathrm{~cm}$ de cumprimento, apresentava marcas de raspagem em um dos lados, sugerindo ter sido utilizado para a produção de pigmentos. Com todos esses elementos vestigiais encontrados, ficou configurado um contexto nítido de atividade pictórica, passível de ser datado por C14, através dos carvões da fogueira.

Apesar da segunda fogueira da quadra número 9 ter sido também datada, não foram encontrados materiais referentes à produção de pigmentos para as pinturas. De modo que só pode se conhecer a existência de um grupo humano centenas de anos depois, registrada apenas pelo fato da construção de estrutura de combustão, Amostras do carvão encontrado nas duas fogueiras foram enviadas ao Laboratório de Gif sur Ivette, na França, e tratadas pelo Dr. Michel Fontugne. As idades obtidas pelo método de C14, correspondem a $2.470+-30$ anos BP e Cal BP e $990+\_35$ anos BP. Ou seja, no sítio Toca da Figura atestam-se dois momentos de ocupação 
diferenciados, no primeiro dos quais praticou-se a atividade pictórica, comprovada pela presença de dos bloquinhos de pigmento.

Com o objetivo de estabelecer a relação entre as pinturas e os blocos de pigmentos encontrados dentro das fogueiras durante as escavações arqueológicas e assim verificar a possível existência de similaridade desses pigmentos e, consequentemente, a contemporaneidade entre a fogueira e os motivos pintados, procedeu-se a análises químico-mineralógicas de amostras de diferentes cores e tonalidades dos pigmentos rupestres, coletadas nos conjuntos gráficos próximos à fogueira. Ademais, analisaram-se as duas amostras de argila compactadas, denominadas de blocos de pigmentos, oriundas das fogueiras evidenciadas nas escavações arqueológicas.

O objetivo foi encontrar marcadores químicos que pudessem indicar se havia relação entre as pinturas rupestres e as amostras de ocre associadas à fogueira, pois assim se poderia inferir a temporalidade entre a datação de C 14 e o momento de pintura de algum dos grafismos rupestres do sítio Toca da Figura.

A seguir, apresentam-se descritas as amostras estudadas, que correspondem a uma representação de cada cor ou variedade de tonalidade observada no sítio Toca da figura. 


\section{Descrição das amostras}

Foram coletadas 12 micro-amostras de diferentes cores e tonalidades de pigmentos rupestres em figuras com representações estilísticas variadas (Figura 1).
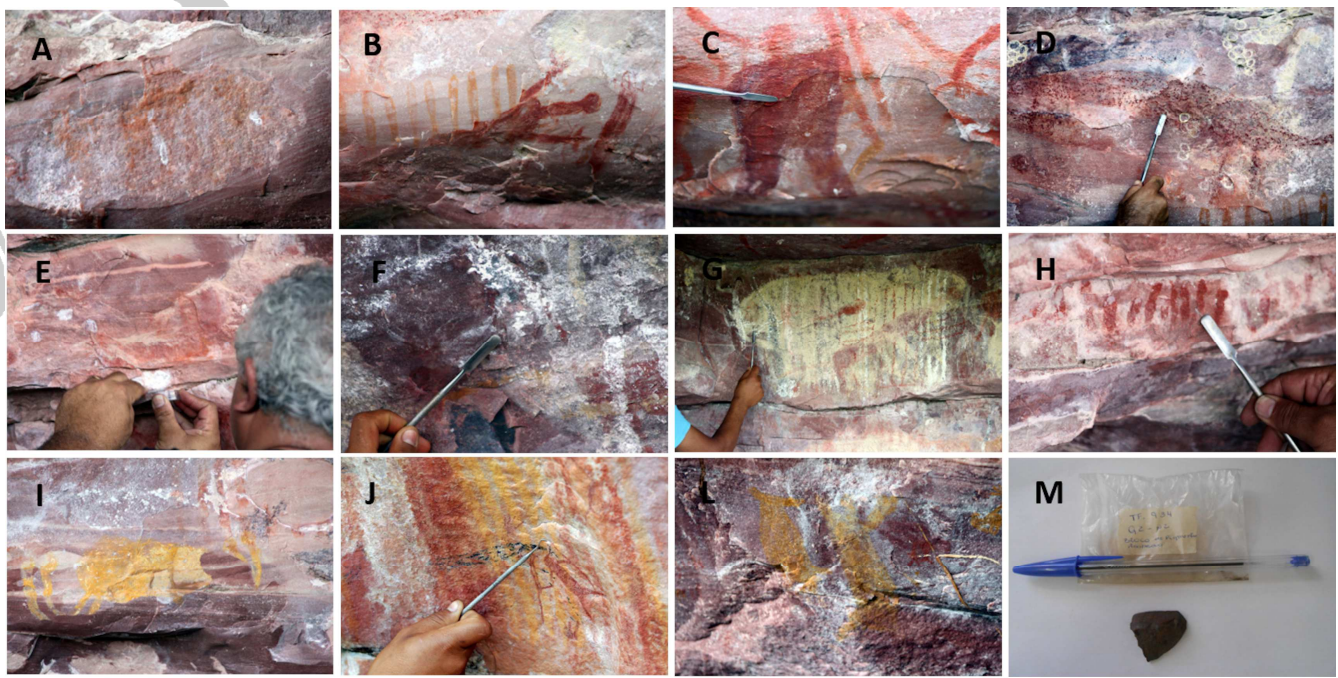

M

N
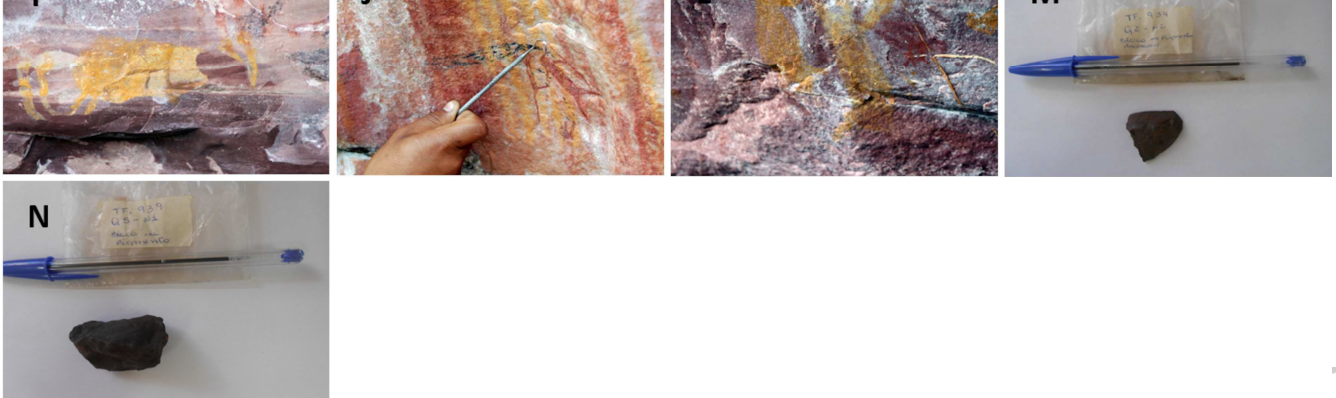

Figura 1. Imagem das figuras de pigmentos amostrados ( A -L) e dos ocres ( $\mathrm{Me}$ N).

A descrição das amostras de pigmentos com as características dos grafismos consta no Quadro 1.

\begin{tabular}{|c|c|}
\hline AMOSTRAS & CARACTERÍSTICAS \\
\hline Amostra 1 & vestígios de pinturas vermelho claro \\
\hline Amostra 2 & antropomorfo vermelho médio \\
\hline
\end{tabular}


Clio Arqueológica 2020, v35N1, p.14-38, ETCHEVARNE; LAGE; FARIAS FILHO; SANTOS DOI: 10.20891/clio.V35N1p14-38

\begin{tabular}{|c|c|}
\hline Amostra 3 & fila de antropomorfos alaranjados \\
\hline Amostra 4 & antropomorfo vermelho médio a escuro \\
\hline Amostra 5 & desenho tipo crayon vermelho escuro \\
\hline Amostra 6 & vestígios de pigmentos brancos \\
\hline Amostra 6A & $\begin{array}{l}\text { pigmento branco com suporte rochoso (depósito de alteração } \\
\text { recobrindo pintura vermelha) }\end{array}$ \\
\hline Amostra 7 & zoomorfo da tradição Agreste de cor bege \\
\hline Amostra 8 & $\begin{array}{l}\text { fileira de antropomorfos miniaturizados de cor vermelha } \\
\text { escura }\end{array}$ \\
\hline Amostra 9 & zoomorfo de cor amarela \\
\hline Amostra 10 & antropomorfo de cor vermelha arroxeada e \\
\hline Amostra 11 & figura preta superpondo pigmentos amarelo e vermelho \\
\hline Amostra 12 & antropomorfo amarelo \\
\hline Amostra de ocre (TF934) & Ocre \\
\hline Amostra de ocre (TF939) & Ocre \\
\hline
\end{tabular}

Quadro 1. Descrição das micro-amostras e suas respectivas características.

As micro-amostras foram descritas com o auxílio de um microscópio portátil (ProScope HR CSI) com conexão USB ao computador. As imagens foram obtidas utilizando uma lente (Scalar) de aumento de 30x realizando uma observação minuciosa dos pigmentos e dos ocres. Tais observações permitiram visualizar informações como aspectos de aderência das tintas, desgastes por agentes antrópicos e naturais bem como o caso de sobreposição de cores.

Para estudo do realce das cores da arte rupestre foi aplicada a técnica de processamento de imagens utilizando o filtro YYE do plugin DStretch ${ }^{\circledR}$, uma ferramenta de melhoramento de imagens baseada no estiramento de correlação 
(Evans e Mourad, 2018; Harman, 2005). Tal técnica permite verificar aspectos como os problemas de desgastes naturais ou antrópicos, sobreposição de tintas, distinção de cores (Evans e Mourad, 2018; Palomar-Vasquez et al., 2017; McDonald et al, 2016; Gun e Douglas, 2014).

A identificação da composição química elementar e mineralógica foi realizada utilizando as técnicas: espectroscopia de emissão óptica em plasma induzida por laser (LIBS), espectroscopia de Fluorescência de Raios X portátil, espectroscopia Raman e infravermelho. A análise por LIBS (home lab) foi realizada sem tratamento de amostra, com energia de $60 \mathrm{~mJ}$ e tempo de delay e integração de 0,5 $\mu \mathrm{s}$, do mesmo modo a análise por Fluorescência X não necessitou de preparo das amostras. Foi utilizado um sistema de FRX portátil (Thermo Fisher Scientific, Niton XL3t Ultra) equipado com tubo de raios X com um anodo de prata. As análises foram realizadas sob as seguintes condições: voltagem máxima de $50 \mathrm{kV}$, corrente de $200 \mu \mathrm{A}$, tempo de medida de 120 segundos e área de irradiação sobre a amostra de cerca de $29 \mathrm{~mm}^{2}$. Os espectros Raman foram obtidos na linha de laser de $785 \mathrm{~nm}$, potência de 50 a $100 \mathrm{~mW}$ e tempo de integração de $10 \mathrm{~s}$. Já as análises por infravermelho demandaram uma preparação prévia sob a forma de pastilha de $\mathrm{KBr}$, no modo de transmitância, na faixa de 4000 a $450 \mathrm{~cm}^{-1}$.

\section{Resultados obtidos}

A Figura 2 apresenta os resultados da análise química elementar das amostras de pigmentos rupestres e dos ocres. 


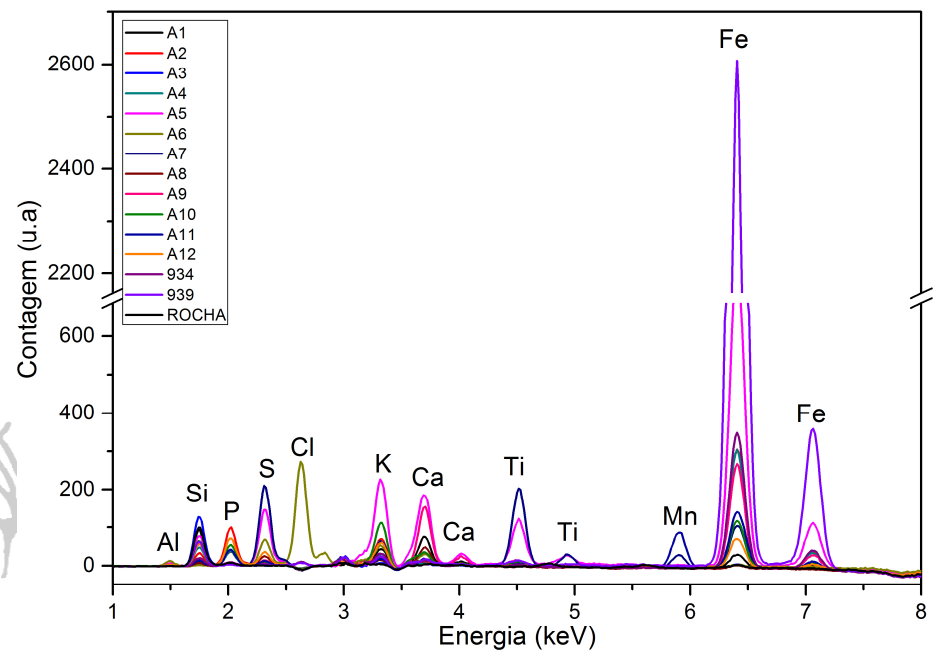

Figura 2 - Espectros por Fluorescência x portátil das amostras

Como já se dispunha de amostras, elas foram analisadas em laboratório por um equipamento de Fluorescência de Raios X portátil e o pico referente ao elemento manganês presente na amostra 11 de coloração preta indica a utilização de matéria prima a base de óxido de manganês para as tintas pretas e não de carvão vegetal, como foi utilizado em outros sítios do Nordeste brasileiro. Em relação aos pigmentos vermelhos e amarelos observou-se que são compostos basicamente de óxidos de ferro, variando apenas o teor de outros elementos, como por exemplo o potássio e o cálcio. Tal similaridade sugere que foram realizados com argilas minerais retiradas de uma mesma jazida. Os pigmentos vermelhos são bastante similares aos ocres encontrados próximos à fogueira, principalmente ao da amostra 939. O pigmento branco é a base de óxido de alumínio, típico de depósitos de alteração, portanto é possível que neste sítio esta cor tenha sido elaborada com material do próprio sítio. 
A Figura 3 indica os detalhes morfológicos, com aumento de 30x, das amostras de pigmentos $(\mathrm{A}-\mathrm{N})$ e dos ocres $(\mathrm{O}-\mathrm{P})$.

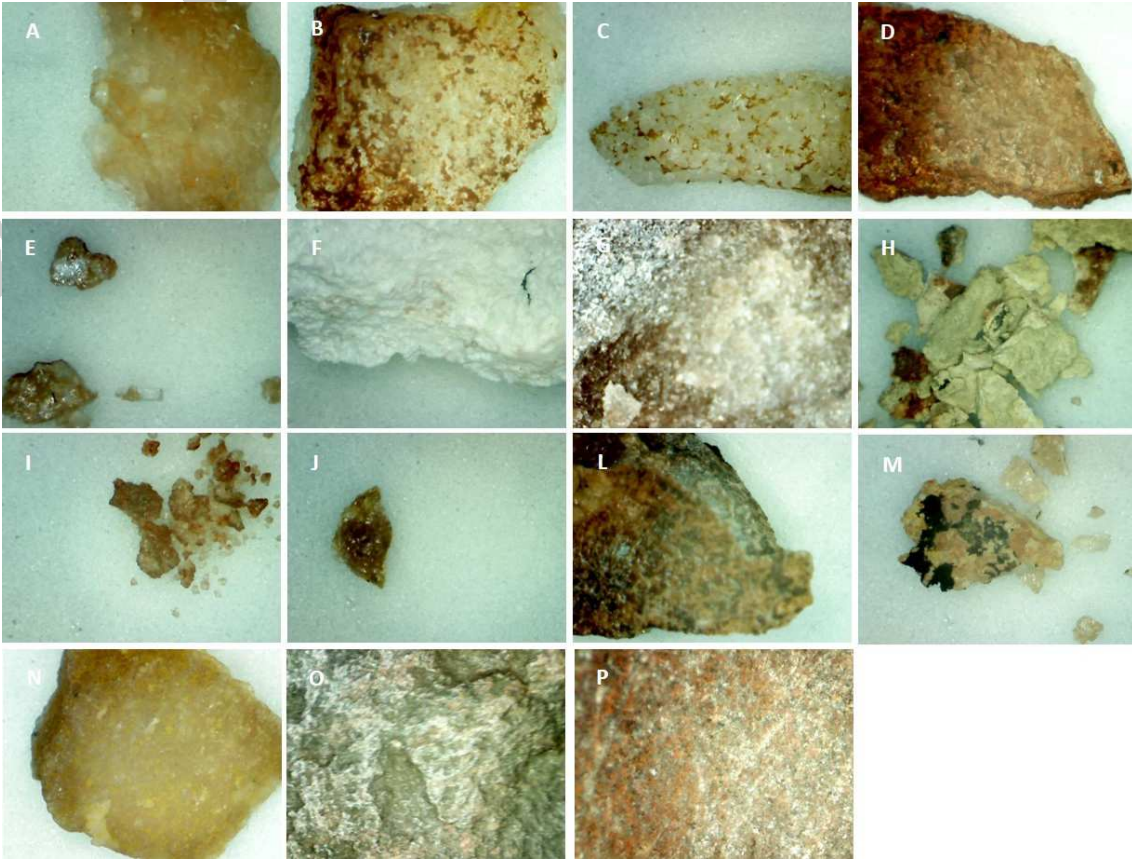

Figura 3.

Exame sob microscopia óptica USB com aumento de 30 x para as amostras de pigmentos $(\mathrm{A}-\mathrm{N})$ e de ocres (O-P).

A avaliação

microscópica dos pigmentos rupestres relevou que as tintas se encontram dispersas na matriz rochosa devido aos desgastes que as figuras rupestres lidaram por estar expostas aos intemperismos naturais. Observa-se ainda a presença de alguns pontos brancos, que estão relacionados a eflorescências salinas que acabam por encobrir o painel rupestre. As amostras de ocres (O-P) caracterizadas como uma massa 
compacta de colorações distintas, uma mais escura que a outra podem ter sido geradas pela ação do ambiente de combustão em que se encontravam.

A Figura 4 apresenta as fotografias após tratamento de imagem por DStretch usando o filtro YYE.
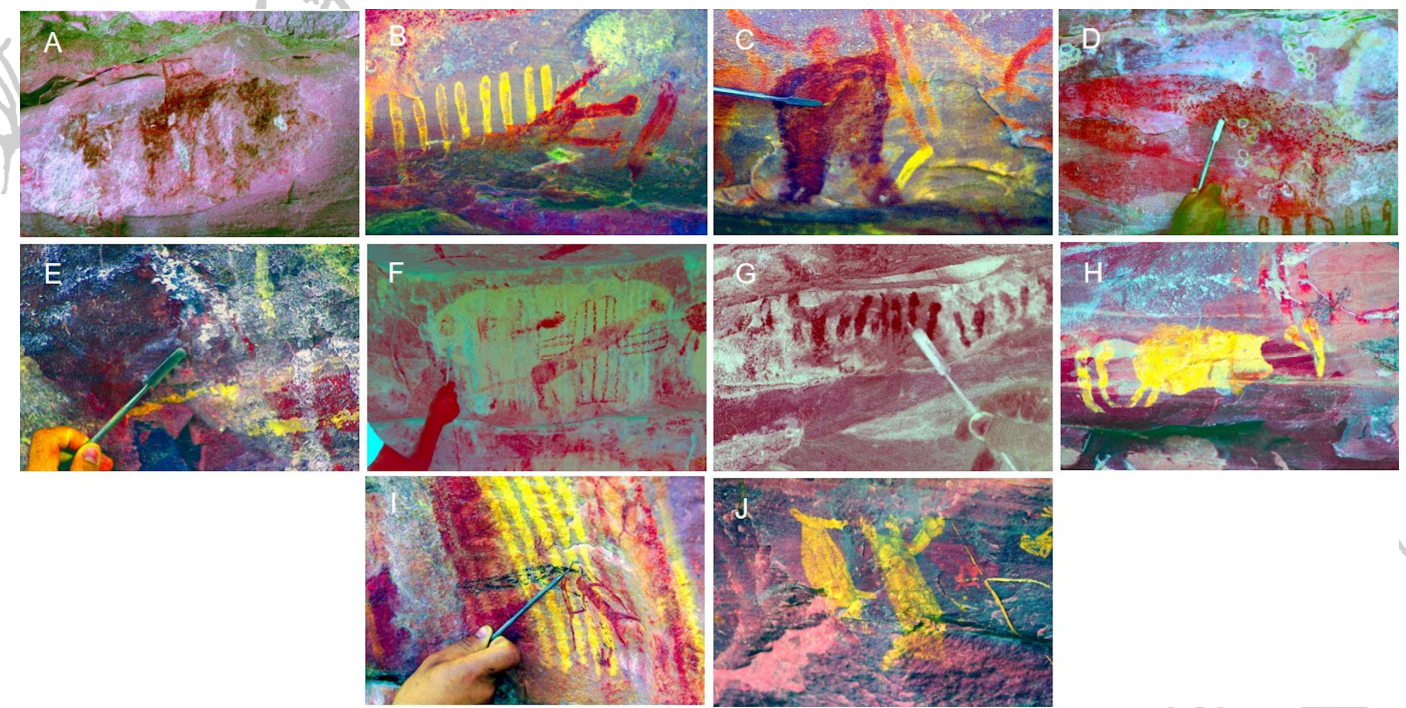

Figura 4. Imagens das amostras das figuras rupestres após tratamento utilizando o plugin DStretch.

Como pode ser observado na Figura 4, o tratamento de imagem por filtros DStretch permitiu obter os detalhes gráficos não visíveis a olho nu, como a riqueza policromática encontrada no sítio em estudo, amarelas (pintura rupestre da amostra $4 \mathrm{~A}$ - Figura 4E), vermelhas (pintura rupestre das amostras 1 e 7 - Figuras $4 \mathrm{~A}$ e $4 \mathrm{~F}$ respectivamente). Em sua maioria, há sobreposição do pigmento vermelho sobre os 
demais. Na policromia do painel das amostras 2 (Figura 4B) e 3 (Figura 4C), percebe a intencionalidade do aproveitamento do suporte rochoso desplacado para a aplicação do pigmento amarelo.

\section{Pigmentos vermelhos (amostras 1, 2, 4, 5, 8, 10), bege (amostra 3) e amarelo} (amostra 9 e 12) a base de ferro:

A avaliação da composição química elementar das tonalidades das amostras vermelhas $(1,2,4,5,8,10)$, bege (3) e amarelos ( 9 e 12) foi analisado por LIBS cujo resultado é apresentado na Figura 5.

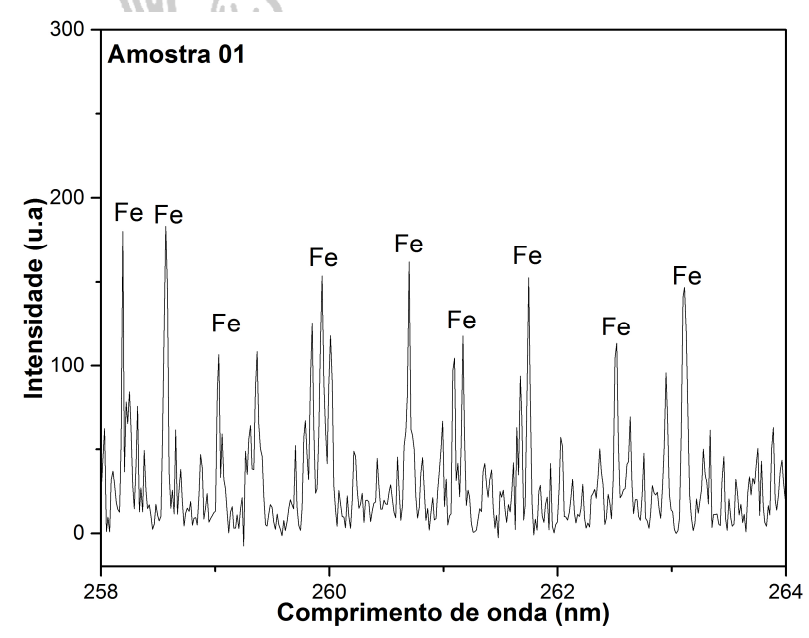

Figura 5. Espectro elementar LIBS da amostra 01 com destaque para o elemento Ferro.

Como pode ser observada, na Figura 5 foi selecionada a faixa de comprimento de onda de 258 a $264 \mathrm{~nm}$ para avaliar a presença do ferro cujas linhas espectrais assinaladas confirma a presença desse elemento como material pigmentante em todas as amostras de coloração vermelha, amarela e bege analisadas. 
Os resultados obtidos por espectroscopia Raman para os pigmentos vermelhos são apresentados na Figura 6.

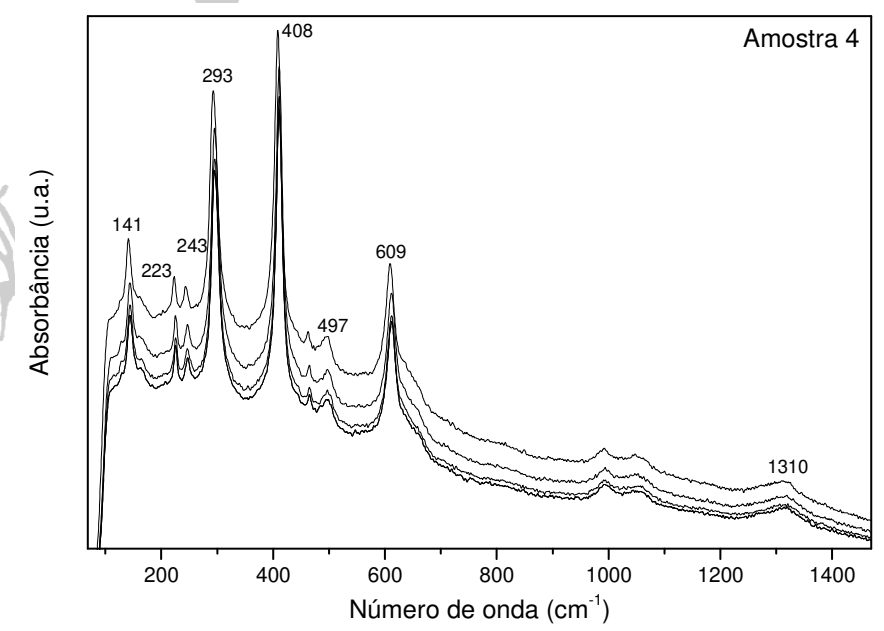

Figura 6. Espectro Raman da Amostra 04.

Os resultados das análises obtidas por Raman mostram a presença de pelo menos três componentes presentes nos pigmentos vermelhos: anatase, hematita e carbono amorfo. A banda característica de anatase ocorre em $141 \mathrm{~cm}^{-1}$ referente ao estiramento Ti-O; a hematita $\left(\mathrm{Fe}_{2} \mathrm{O}_{3}\right)$ é identificada com as bandas ao redor de 223 , 243, 293, 408, 497 e $609 \mathrm{~cm}^{-1}$ que está relacionado ao modo de vibração de Fe-O; por fim, a banda larga ao redor de $1310 \mathrm{~cm}^{-1}$ é característica da banda D de carbono amorfo. É importante citar que a ausência da banda em $970 \mathrm{~cm}^{-1}$ (estiramento de $\mathrm{PO}_{4}{ }^{3-}$ ), indica que o material não oriundo de queima de ossos, mas de material vegetal. 


\section{Pigmento branco (amostras 6 e 6A):}

A análise química mineralógica da amostra de pigmento branco é apresentada na Figura 7.
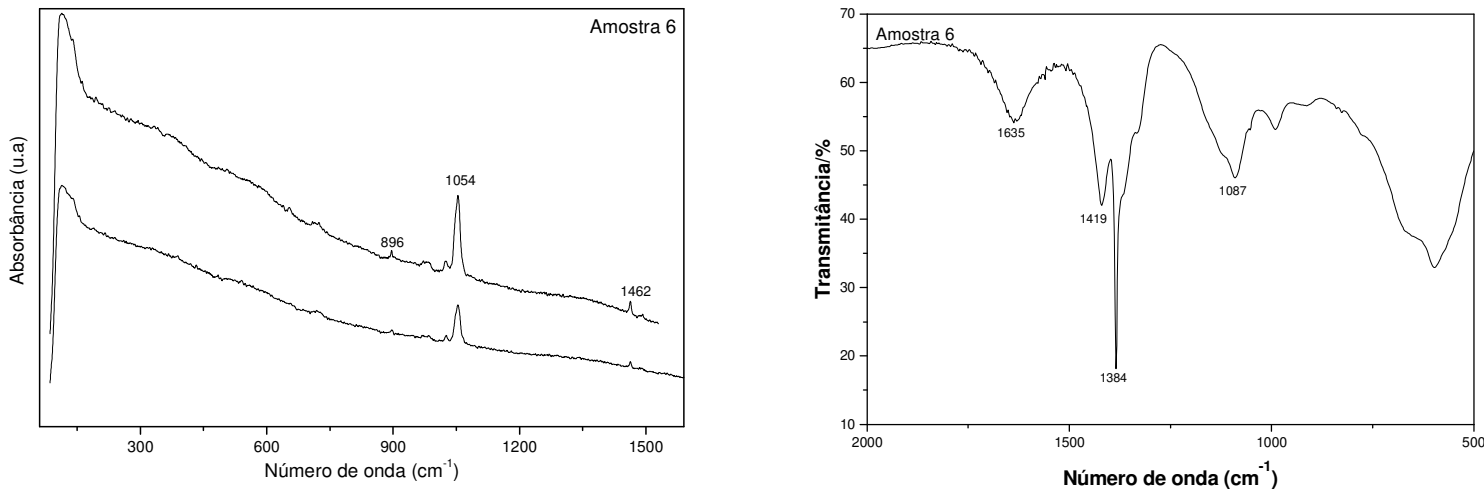

Figura 7. Espectros Raman e Infravermelho da Amostra 06.

As bandas Raman e no infravermelho indicam que o pigmento branco é composto de uma mistura de sais como a wewelita $\left(\mathrm{CaC}_{2} \mathrm{O}_{4} \cdot \mathrm{H}_{2} \mathrm{O}\right)$ e carbonato de cálcio $\left(\mathrm{CaCO}_{3}\right)$. Os modos vibracionais de $\mathrm{C}-\mathrm{O}$ de estiramento simétrico da wewelita no espectro Raman é observado nas bandas em 1462 e $1054 \mathrm{~cm}^{-1}$ e o estiramento C-C é encontrado em $896 \mathrm{~cm}^{-1}$.

O espectro de infravermelho da amostra 6 (pigmento branco) apresenta bandas de estiramento de $\mathrm{C}=\mathrm{O}$ em $1635 \mathrm{~cm}^{-1}$; em $1419 \mathrm{~cm}^{-1}$ é associada ao modo vibracional de estiramento antissimétrico C-O; a banda em $1635 \mathrm{~cm}^{-1}$ é característico de estiramento simétrico C-O e por fim, a banda em aproximadamente $1390 \mathrm{~cm}^{-1}$ é 
referente ao estiramento simétrico de C-O-C. Tais informações permitiram identificar que o pigmento branco também é composto de calcita $\left(\mathrm{CaCO}_{3}\right)$.

\section{Argila compactada (amostras TF934 e TF939):}

A Figura 8 apresenta o resultado obtido por espectroscopia Raman de duas amostras de argilas com marcas de combustão e que foram coletadas durante a sondagem arqueológica.
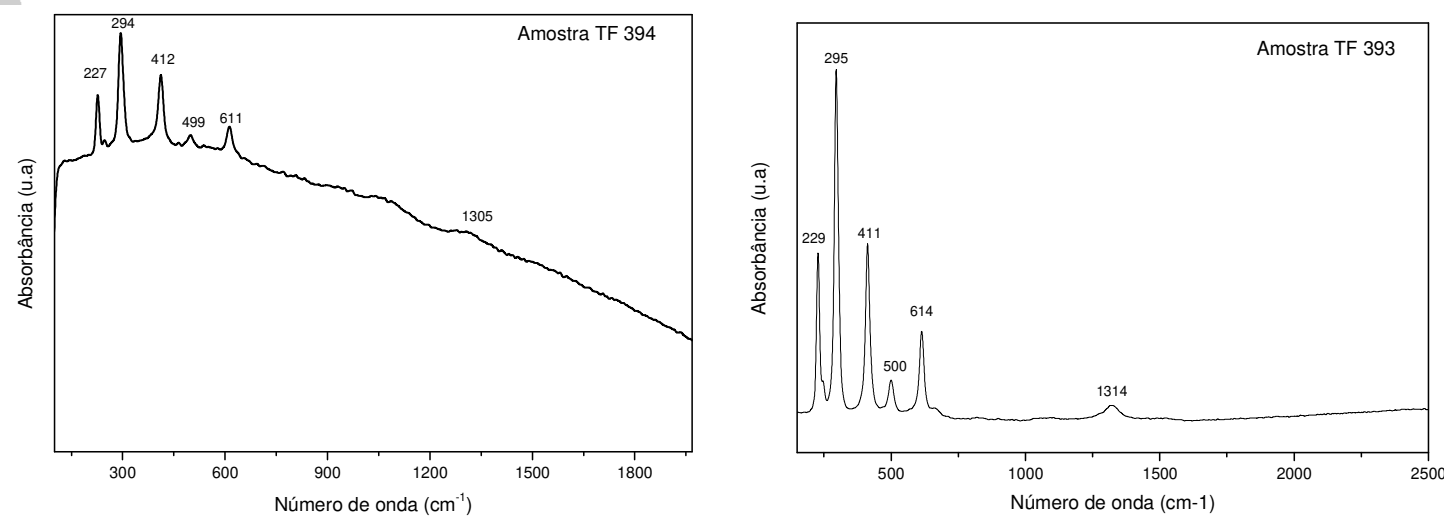

Figura 8. Espectros Raman das Amostras de ocre.

Os sinais Raman em 227, 294, 412, 499 e $611 \mathrm{~cm}^{-1}$ são devido ao modo de vibração do Fe-O de hematita. $\mathrm{O}$ sinal observado ao redor de $500 \mathrm{~cm}^{-1}$ indica a presença de silicatos, e a banda ao redor de $1300 \mathrm{~cm}^{-1}$ é característico de carbono amorfo. Portanto, as amostras de argilas trata-se de uma mistura de hematita com silicatos. 
De forma resumida, as análises utilizando as técnicas de espectroscopia Raman, LIBS e IV indicaram que os pigmentos vermelhos são a base de hematita, tendo em um deles a presença de carbono amorfo; o branco é constituído de wedelita, anatase e carbonato de cálcio e as duas amostras de argila compacta oriundas da sondagem arqueológica indicaram a presença de hematita e carbono amorfo.

\section{Considerações finais}

As análises por espectroscopia Raman indicaram que a composição química mineralógica dos blocos de argila e das pinturas vermelhas são idênticas, ou seja, a base de hematita e silicato. Principalmente a amostra TF 939, mais rica em hematita pouco cristalizada, típica de pigmentos rupestres. A presença do carbono amorfo nas amostras de argila compactada e em pigmentos rupestres são também indícios da relação entre a arte rupestre do sítio e a fogueira. Todavia é recomendável dar continuidade às investigações, levando para o campo equipamentos analíticos portáteis de outras técnicas de análise, como por exemplo, espectroscopia Mossbauer (MIMOS 2) e Fluorescência X, o que auxiliaria mais na afirmação das relações de identidade e não identidade entre as pinturas e as concreções de argila encontradas na fogueira. O sítio Toca da Figura é detentor de uma real possibilidade de efetuar uma datação da arte rupestre de pelo menos duas diferentes tradições, a Nordeste e a Agreste. No entanto, deve-se considerar o fato de se ter encontrado carbono amorfo nas análises químicas por espectroscopia Raman em amostras de pigmentos vermelho e amarelo, ou seja, especificamente nas amostras 4, 12 e $6 \mathrm{~A}$, esta última correspondente a uma eflorescência salina branca do depósito rochoso 
que recobre pinturas. Isto permite afirmar que há vestígios de fuligem oriundos do uso da fogueira recobrindo a parede pintada.

Tal fato possibilita conjecturar que a presença do carbono amorfo recobrindo parte dos grafismos indica que a fogueira foi acesa após sua realização, permitindo assim efetuar uma datação relativa de pinturas rupestres do sítio, ou seja, elas já tinham sido elaboradas quando a fogueira foi acesa pela última vez.

\section{REFERÊNCIAS BIBLIOGRÁFICAS}

ETCHEVARNE, Carlos. 2007. Escrito na Pedra. Cor, forma e movimento nos grafismos rupestres do Estado da Bahia. Versal, Rio de Janeiro. 2007

J. MCDONALD, A. CATACORA, S. de KORNING, E. MIDDLETON, J. Archaeol. Sci. Reports, 2016, 10, 917.

L. EVANS, A. MOURAD, J. Archaeol. Sci. Reports, 2018, 18, 78.

J. PALOMAR-VAZQUEZ, S. BASELGA, M. J. VIÑALS-BLASCO, C. GARCÍASALES, I. SANCHO-ESPINÓS, J. Archaeol. Sci. Reports, 2017, 12, 32.

R. G. GUNN, L. C. DOUGLAS, R. L. WHEAR, Rock Art Res., 2014, 31 (1), 1.

J. HARMAN, Using decorrelation Stretch to enhance rock art imagens, Annual Meeting of the American Rock Art Research Association, Reno, Nevada, 2005.

PESSIS, Anne M. Imagens da Pré-história. Fundham. Rio de Janeiro, 2002. 